\title{
THE PRESERVATION OF CONTRACTILE MARINE ANIMALS IN AN EXPANDED CONDITION
}

\author{
By H. A. F. Gohar, M.Sc., Cairo
}

The importance of killing contractile animals in an expanded condition cannot be over-estimated. A glance at the immense confusion and uncertainty which prevails in several branches of tropical marine invertebrates, and in particular the Coelenterata, will give a clear picture of the value of good preservation. Killing contractile animals in an expanded condition has always offered considerable difficulty. Several methods have been recommended for different animals, but it is often very difficult to choose the appropriate one, since animals belonging to one and the same group may behave quite differently towards any method. The writer, during his work for the last three years at the Marine Biological Station of the University of Cairo at Ghardaqa ${ }^{\star}$ in the Red Sea, has taken great pains to preserve a variety of marine invertebrates as fully expanded as possible. Some of the successful results and the methods used are therefore given here.

The commonest method for the present purpose is the use of narcotics. The most familiar of these are menthol, chloral hydrate, alcohol, magnesium sulphate and cocaine. Owing to the difficulty in obtaining cocaine it cannot be freely used for general purposes. Menthol enjoys a great reputation for narcotization which, in fact, it does not quite deserve. Although in some few cases it gave good results, yet in the majority it was quite unsatisfactory, as delicate animals begin to macerate before they are properly narcotized. It is generally applied in the crystal form and sprinkled on the surface of the water. Apparently its low solubility is responsible for a great many of its failures. This difficulty of solution was sometimes overcome by using an alcoholic solution of menthol and spreading it on the surface of the water. Better results were obtained in this way with some nudibranchs and alcyonarians.

Chloral hydrate and alcohol were used for various animals but with little success. Chloroform vapours were useful in killing crabs without breaking their legs.

Magnesium sulphate is the most popular of all narcotics for marine animals, and in fact it deserves its popularity, as it gives satisfactory results with a great variety of animals. It is, however, essential that the animal to be narcotized should be put in plenty of clean sea water and the salt be added gradually at intervals of about Io min. or so. The time required for complete narcotization

\footnotetext{
* Hurghada on charts.
} 
differs with the kind and size of the animals, but is generally between 5 and 24 hours. It is best to put the narcotic in a corner of the vessel farthest from the animal. To avoid fractional addition of magnesium sulphate the required quantity may be packed up in a bag of fine-meshed gauze and the latter put into the vessel containing the animals to be narcotized, also at a corner farthest from the animals.

By this method the giant nudibranchs, Hexabranchus sanguineus, Thordisa crosslandi and Asteronotus hemprichi, also Doridopsis nigra, Pleurobranchus delicatus, the pulmonate Oncidium sp., the placophores Acanthochiton spinigera and other chitons were successfully killed. Among the Madreporaria, Goniopora columna - which is fully expanded in the sea in full sunlight-Fungia sp., Turbinaria mesentrina, Favia sp. and others give satisfactory results after narcotization with magnesium sulphate.

Planarians are usually successfully killed by hot sublimate solution without previous narcotization. Sometimes, however, it is desirable to avoid the use of sublimate. They can easily be narcotized with magnesium sulphate, spread on a glass slide and killed with whatever fixative may be required.

Of the Alcyonaria, Tubipora musica, Acabaria pulchra (Hickson, 1937), Clathraria rubinoides, four species of Sympodium and two species of Clavularia, all of which are completely retractile, lend themselves easily to this method of narcotization. It is of very little value, if any at all, with other alcyonarians such as all species of the genera Alcyonium, Sarcophytum, Lobophytum, Sinularia, Dendronephthya and others. The animals never remain fully expanded after the addition of the narcotic, and, moreover, they usually macerate before they are sufficiently narcotized.

There is, however, one drawback to the use of this method, and this is that a great amount of the salt has to be used-about I $50 \mathrm{~g}$. or more per litre of sea water. The great osmotic pressure it develops and the very long time through which it has to act are liable to make major changes in the delicate structures of the tissues, thus rendering animals killed by this method of little value for cytological or even histological purposes.

Another method, which proved quite satisfactory and at the same time has not the drawbacks mentioned above, was, as far as the writer is aware, used here for the first time. This is accomplished by killing the animals gradually and insensibly by formalin. The method is summarized as follows. The animal is put in a great bulk of sea water 50-500 times its volume or more. After it has properly expanded a few drops of dilute formalin are added (3 drops of I \% formaldehyde to 100 c.c.), and this is repeated at intervals of about $15 \mathrm{~min}$. The amount of formalin added may be doubled every hour. The animal eventually dies with but very little or no contraction.

Two species of Aeolis have defied every other method. The cerata fall off at the slightest disturbance, even the transfer from one aquarium to another is quite sufficient to cause the withering of some cerata. All sorts of narcotics have the same effect. These two species of Aeolis lend themselves to the gradual 
action of formalin in a remarkable manner and are killed in a perfect condition. The only other method to which these two aeolids yield is freezing and thawing the frozen mass in strong formalin, as will be mentioned below.

Other examples of animals that yield to the gradual poisoning by formalin are Hexabranchus sanguineus, Doridopsis nigra, Oncidium sp., Acanthochiton spinigera, Acabaria pulchra, Sympodium coeruleum, etc. The ophiuroid Astroboa sp. also yields to this method, but this animal should be left to expand in a flat dish and the excess of water siphoned off, leaving just enough to cover the animal; the formalin is then applied.

Some animals, such as the anemones Actinia quadricolor and Thalassianthus aster, are extremely sensitive to great dilutions of formalin and at the same time could not readily be sufficiently fully anaesthetized by any narcotic. These, however, respond well to partial narcotization with magnesium sulphate together with the treatment with formalin described above. The magnesium sulphate thus reduces the sensitivity of the animals to the gradual poisoning by formalin.

Narcotization by freezing seems to be a very promising method and deserves some effort towards its development and the generalization of its use. It has the advantage that animals are not liable to any maceration during the process, and accordingly the finer structures of the tissues are likely to be better preserved than by any other method. The effect of low temperatures on marine animals is a point of extreme interest and importance, but unfortunately till now has not been thoroughly worked out. It is very probable that better knowledge of the temperature relations of these animals may give the clue to the successful killing of a great variety of marine invertebrates in an expanded condition. Preliminary attempts in this respect give us much hope. Many animals-some of them defy all other methods-are very successfully killed after freezing. The animals are put in plenty of clean sea water in a glass vessel. The latter is in its turn put into an ice chest till the water becomes ice cold; it is then transferred to a freezing mixture and left to freeze. After some time the frozen mass is taken out of the freezing mixture, and as much of the ice as possible is allowed to melt away without exposing the animals. The latter, embedded in just enough ice, are thrown into a strong fixation solution, e.g. fairly strong formalin, where the ice is allowed to thaw. By this method the two species of Aeolis - which yield only to gradual poisoning by formalin-are killed in the most perfect condition. Glossodoris quadricolor, Chromodoris annulata, several tritonid species and many other nudibranchs are killed in such an expanded condition unparalleled by any obtained by other methods. Some actinians, particularly small and moderately sized ones, were well expanded after preservation. In many cases lowering the water temperature even to freezing-point does not seem to be sufficient, as some animals seem to resist this temperature. They will move as soon as the temperature rises, and if killed at such low temperatures they will still shrink. Animals kept on ice overnight contracted when put into the fixative next morning. Freezing 
is, therefore, evidently essential, at least for some animals. It may be that freezing mechanically prevents the contraction of the animals on the application of the fixative, as the latter will act on any part of the animal immediately it is exposed, while the rest will be held by the frozen mass. It may be remarked here that the resistance of some of these tropical animals to low temperatures is surprising.

A method which proved very useful in killing a large variety of marine animals and which possesses the advantage of rapidity is the instantaneous killing by using boiling strong formalin. Hot fixatives have been used for killing animals that contract slowly, but even then the way they are used is bound to induce a certain amount of contraction in the process of removing the animals from the water and dropping them into the fixative. Here it is the fixative that is poured on the animals. The latter are put in a vessel just large enough to allow them to expand freely. The vessel ought to be about three times as high as the animals. The whole vessel may then either be put into a large aquarium with running sea water or the water be directly run into it according to the nature of the animals. When the animals have completely expanded, the vessel is removed very carefully from the aquarium or the running water stopped. The water in the vessel is very carefully run out by means of a siphon, without causing any disturbance to the animals, until just enough is left to cover the animals completely. A sufficient volume of concentrated formaldehyde solution (one-third to one-half the volume of the water containing the animals to be killed) at the boiling-point is now rapidly poured into the vessel. The animals are thus instantaneously killed without having any time to contract. They are then removed as rapidly as possible to the required preservative.

By this method the anemone Thalassianthus aster and the colonial anemones Palythoa tuberculata and Palythoa sp. were killed in a most perfectly expanded condition. Several other small anemones gave very good results. It always, however, failed with Calliactis polypus (commensal anemones with the hermit crab Pagurus tinctor) and the large anemones Discosoma giganteum, Actinia quadricolor, Paractis adherens, $P$. hemprichi and others. Among the Madreporaria Fungia sp. and Goniopora columna are killed in this way with little contraction. For the Alcyonaria, however, no other method compares with this. Alcyonium, Sarcophytum, Lobophytum, two species of Clavularia, four species of Sympodium, Acabaria pulchra (Hickson, 1937), Acabaria sp., Tubipora musica, and also hydroids, all give strikingly good results.

The majority of the nudibranchs do not lend themselves to this method, and all those tried contracted very badly on the addition of boiling formalin.

The use of boiling concentrated formalin has, unfortunately, the great disadvantage of being extremely irritating, and considerable care has to be taken in the manipulations. The formalin has to be boiled in a narrow-mouthed flask stoppered with cotton-wool. When the formalin is poured on to the animals, splashing ought to be carefully avoided as it seriously affects the skin. Its vapours are also injurious to the eyes, lungs and the mucous membranes of the 
respiratory system, so that the process may, at best, be carried out in a fume cupboard or, lacking that, a simple device may be used in its place. It is also strongly recommended that the worker should move to the open air immediately he pours the formalin on the animals.

In all the methods described above it is of prime importance that the animals should be fully expanded before the addition of the narcotic or preservative. Contracted animals are, in the overwhelming majority of cases, quite unlikely to expand under the effect of the narcotic. Some animals will not even expand if left in stagnant clean water: running water has to be used. It is therefore inadvisable to put the animals into the narcotizing or fixing solution, the narcotic or fixative has to be added to the water containing the animals. Narcotics or small doses of poisons are to be added very gradually so that the animals may be insensibly narcotized or poisoned. If such animals show any signs of contraction during the process, further addition of the narcotic should be stopped and the animals left undisturbed till they re-expand. Sometimes it is necessary that the narcotic in the water containing the animals should be ciluted by the addition of more fresh sea water, or, the animals may even have to be removed to fresh sea water; then narcotization should be resumed after they have revived completely.

Animals that expand at night should naturally be dealt with at night.

\section{REFERENCE}

Hickson, S. J., I937. The Family Melitodidae. Trans. Zool. Soc., Vol. xxiII, p. I70. 